\title{
Analysis and Modeling of Time-Correlated Characteristics of Rainfall-Runoff Similarity in the Upstream Red River Basin
}

\author{
Xiuli Sang, ${ }^{1,2}$ Jianxin Xu, ${ }^{1,2}$ Kun Zhang, ${ }^{3}$ and Hua Wang ${ }^{2}$ \\ ${ }^{1}$ Quality Development Institute, Kunming University of Science and Technology, Kunming 650093, China \\ ${ }^{2}$ Engineering Research Center of Metallurgical Energy Conservation and Emission Reduction Ministry of Education, \\ Kunming University of Science and Technology, Kunming 650093, China \\ ${ }^{3}$ Hydrology and Water Resources Bureau of Yunnan, Kunming 650106, China \\ Correspondence should be addressed to Jianxin Xu, xujianxina@163.com
}

Received 25 October 2012; Revised 30 November 2012; Accepted 30 November 2012

Academic Editor: Luis Gimeno

Copyright (๑) 2012 Xiuli Sang et al. This is an open access article distributed under the Creative Commons Attribution License, which permits unrestricted use, distribution, and reproduction in any medium, provided the original work is properly cited.

We constructed a similarity model (based on Euclidean distance between rainfall and runoff) to study time-correlated characteristics of rainfall-runoff similar patterns in the upstream Red River Basin and presented a detailed evaluation of the time correlation of rainfall-runoff similarity. The rainfall-runoff similarity was used to determine the optimum similarity. The results showed that a time-correlated model was found to be capable of predicting the rainfall-runoff similarity in the upstream Red River Basin in a satisfactory way. Both noised and denoised time series by thresholding the wavelet coefficients were applied to verify the accuracy of model. And the corresponding optimum similar sets obtained as the equation solution conditions showed an interesting and stable trend. On the whole, the annual mean similarity presented a gradually rising trend, for quantitatively estimating comprehensive influence of climate change and of human activities on rainfall-runoff similarity.

\section{Introduction}

Understanding the relationships between rainfall and runoff was vital for effective management and utilization of scarce water resources. Especially, it was important in Yunnan where water shortage and drought prevailed in three consecutive years.

In Red River Basin, the changes of watercourse and hydrologic regime, soil erosion, sediment deposition, water pollution, loss of biodiversity, and other cross-border issues have attracted international attention [1]. The protection, rational management, and exploitation of water resources were becoming key issues of the strategic planning in a national level. In the last half century, deforestation and soil erosion were the root causes of drought in Yunnan. Under the influences of climate change and human activities, the ecological environment conditions of the upstream Red River Basin deteriorated further, which directly affected the status of water resources of the middle and lower reaches of the Red River Basin. Precipitation was the main source of Red River Basin water resources. As we all know, rainfall and runoff was correlated and consistent. However, this correlation often displayed a large fluctuation, and the joint effect of climate change and human activities on ecological environment was responsible for the rainfall-runoff relation in the upstream Red River since 2001.

Previous studies [2-5] focused on modeling the rainfallrunoff relations. Generally, these models involved simulation of runoff in a given rainfall sequence. However, most of these studies illustrated that rainfall and runoff presented similar variability. In [6], plots of standardized 1970-2005 annual runoff and rainfall per basin revealed similar variability. Zhang et al. [7] found the rainfall and runoff trends were similar on the whole. But due to complex climate and human activities in different regions, the correlation coefficient of rainfall and runoff showed some fluctuations.

Therefore, the rainfall-runoff similarity was inevitable and should be investigated. Our objective was to define rainfall-runoff flow similarity relationships. In fact, the influence of ecological deterioration and human activities on similarity of rainfall and runoff became more and more prominent. Exploring some time-correlated regularity of 


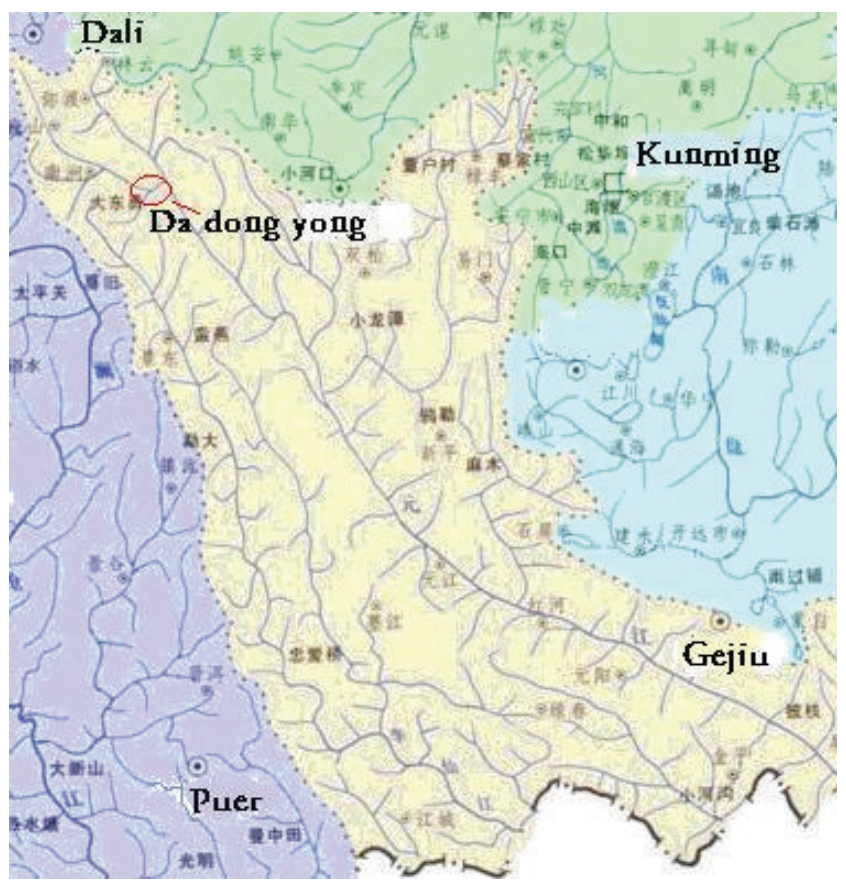

FIGURE 1: Water system diagram of Red River Basin of China.

these fluctuations of rainfall-runoff similarity was a very interesting and challenging work.

Our main contributions are as follows.

(1) We constructed a similarity model based on Euclidean distance between rainfall and runoff (Section 3).

(2) We presented a detailed evaluation of the time correlation of rainfall-runoff similarity (Section 3).

(3) We proposed the annual mean similarity for estimating the joint effects of climate change and of human activities on ecological environment (Section 4).

\section{Data Acquisition}

To investigate the time-correlated characteristics of rainfallrunoff similarity in the upstream Red River Basin of China, we performed a detailed investigation using 10 years (20012010) of daily measurements of rainfall and runoff data as follows.

2.1. Study Area. Figure 1 was the water system diagram of Red River Basin. The Da-dong-yong hydrologic station marked with red circle was located in Najian County of Yunnan Dali Prefecture, at $100^{\circ} 34^{\prime}$ east longitude, $25^{\circ} 04^{\prime}$ north latitude. In 1958 this station was established by the Water Conservancy Bureau of Agriculture Department of Yunnan Province. Since 1988, basic cross-section migrated 87 meters upward, and river basin area reached 2628 square kilometers. It was a typical provincial important hydrometric station in upstream Red River Basin of China. The station was mainly responsible for collecting basic hydrological information in upstream Yuanjiang River of Red River basin, providing services for the protection and exploitation of water resources, flood control, drought, and disaster mitigation.

2.2. Data Processing. The time series of daily rainfall and runoff were obtained from the hydrology stations of Dadongying (Figure 1).

The record ranged from 2001 to 2010, as showed in Figure 2. For time series data, periodical change caused by noise or some mechanism should be determined. We need to find a method to eliminate noise and reflect real trend of hydrological data. Wavelet analysis has been applied in the investigation of the rainfall-runoff relationship [7-9].

In this paper, a denoised time series $X D$ of input signal $X$ was obtained by thresholding the wavelet coefficients.

Signal-to-noise ratio (often abbreviated SNR or S/N) was a measure used in science and engineering that compared the level of a desired signal to the level of background noise. It was defined as the ratio of signal power to the noise power. A ratio higher than $1: 1$ indicates more signal than noise and can be applied to any form of signals.

We defined SNR as

$$
\mathrm{SNR}=\frac{|X|}{|X-X D|}
$$

$X$ represented the vector signal, and the $X D$ indicated the denoised version of input signal.

Figure 3 showed the time series plots of the denoised rainfall and runoff values by wavelet method. By selecting different parameters in wavelet function, a higher signal-tonoise ratio was determined. The SNR of rainfall time series was 18.31, and the SNR of runoff series was 64.25.

Obviously, rainfall and runoff presented periodic change $[10,11]$. However, runoff data showed obvious oscillation and instability, which indicated that runoff was influenced by other factors such as evaporation capacity and vegetation coverage [11].

\section{Modeling}

An analysis of the equal environments assumption should be made. The data of rainfall and runoff were obtained from the hydrology stations of Dadongying in the upstream Red River Basin. Rainfall and runoff in different areas were not analyzed. The numerical similarity between rainfall and runoff was just investigated. The results showed that this numerical similarity based on Euclidean distance was linear. Particularly, the annual mean similarity increase indicated the influence of ecological deterioration and human activities on similarity of rainfall and runoff. In addition, for the noised data, wavelet analysis was used to decrease noise. And signal-to-noise ratio was measured to determine noise level. In Section 4, this paper discussed the impact of noise data on the key parameters of modeling.

First, in this paper the data sets were chosen for exploring the close relationship between rainfall and runoff. More 

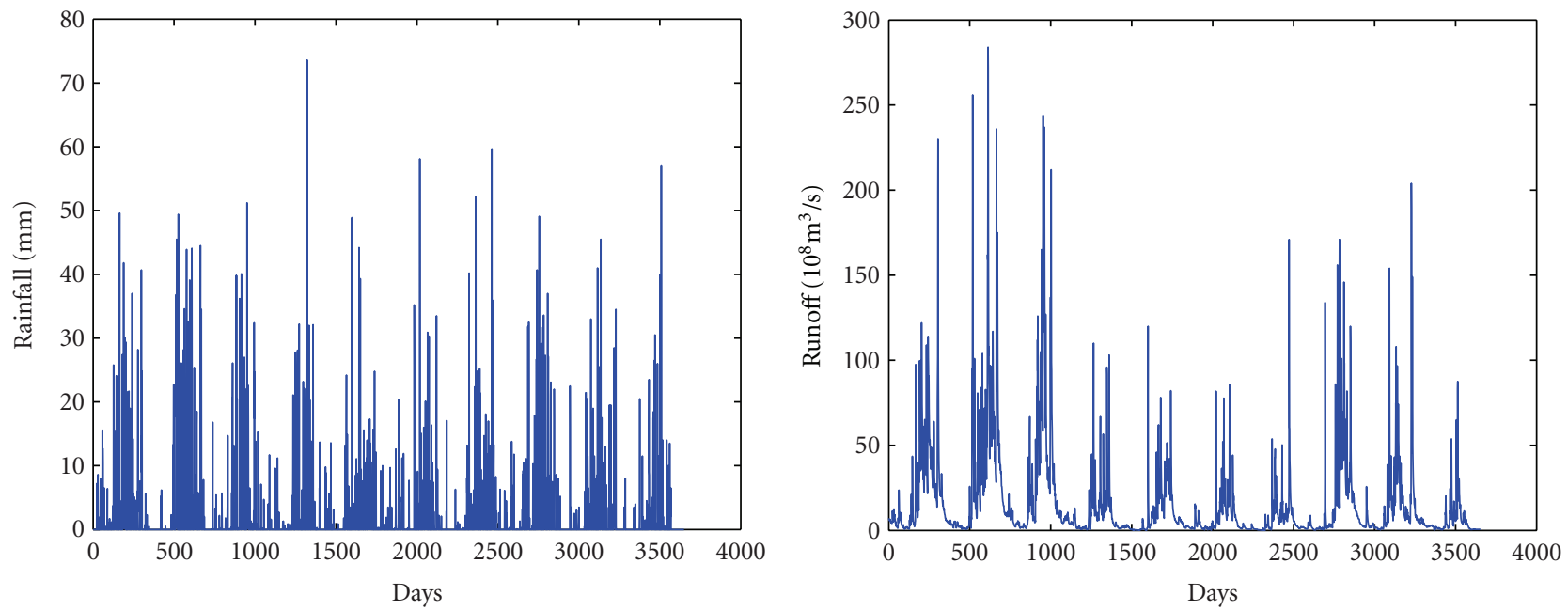

FIGURE 2: Time series plots of the observed rainfall and runoff values.
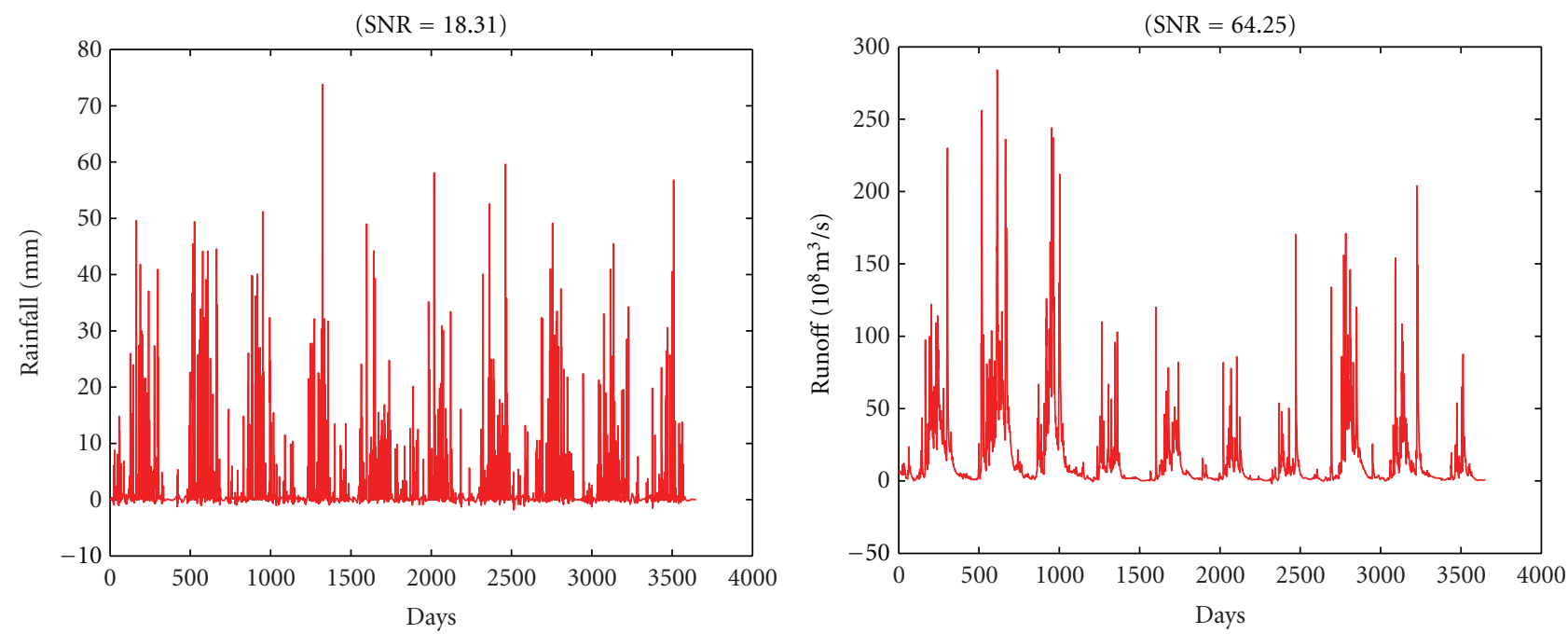

Figure 3: Time series plots of the denoised rainfall and runoff values.

and more studies $[6,7]$ showed that this relationship was important and valuable to acquire the influence of environmental changes and human activities on the ecology. Second, similarity analysis could also be performed by estimating Euclidean distance parameters [12], then the minimum distance between rainfall and runoff sets was defined as similarity, which was obtained by calculating the objective function with absolute value therefore, the particular sets in Table 1 were obtained as the equation solution conditions. Third, the parameters of similarity model were determined by least square method to fit the minimum distance.

The rainfall-runoff modeling contained so many methods [13-19]. This paper investigated a relationship of similarity. Based on the similarity between rainfall and runoff, we need to construct a map for normalizing the data. This mapping could not change the shape of curve, so we used Euclidean distance between the rainfall and runoff to quantify the similarity relation.
Step One. The original and denoised rainfall-runoff signals by thresholding the wavelet coefficients was obtained, as shown in Figures 2 and 3.

Step Two. A normalized data from 10 years of annual rainfall and runoff values was obtained by a linear transformation:

$$
Y=20 X-100 \text {. }
$$

As shown in Figure 4.

Step Three. The Euclidean distance between the normalized rainfall and runoff was calculated, and the minimum value of distance sum was defined as the similarity of rainfall and runoff.

We defined the annual rainfall in 2001 as " $a$," whose coordinate was expressed as $(2001, a)$. The rest of annual rainfall were represented by " $a$." For example, the coordinate in 2002 was written as (2002, $a+821.89)$. Similarly, the annual runoff 
TABLE 1: The corresponding constraints of similarity model in 10 years.

\begin{tabular}{lccccccccc}
\hline 2001 & 2002 & 2003 & 2004 & 2005 & 2006 & 2007 & 2008 & 2009 & 2010 \\
\hline 0 & {$[0,821]$} & 821 & {$[389,821]$} & 389 & {$[0,389]$} & 0 & {$[-35,0]$} & -35 & {$[-35,0]$} \\
0 & {$[0,780]$} & 780 & {$[352,780]$} & 352 & {$[0,352]$} & 0 & {$[-85,0]$} & -85 & {$[-85,0]$} \\
\hline
\end{tabular}

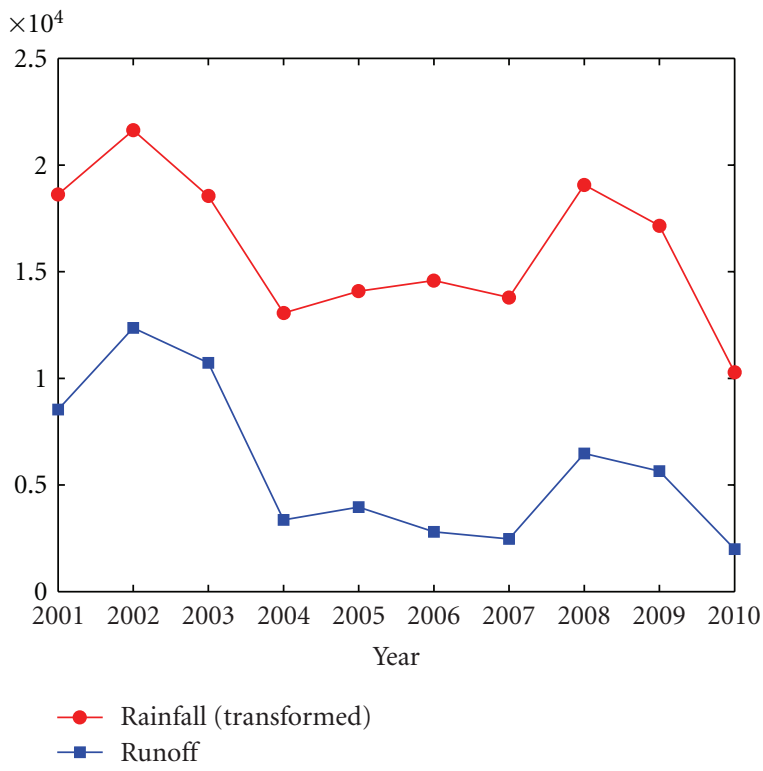

Figure 4: The runoff and transformed rainfall data.

in 2001 was defined as " $b$," and its coordinate was expressed as $(2001, b)$. The rest were represented by " $b$." For example, the Euclidean distance of corresponding points $(2001, a)$ and $(2001, b)$ was calculated by $\sqrt{(2001-2001)^{2}+(a-b)^{2}}$.

Using this transformation, the shape of annual rainfallrunoff curves remained unchanged. The similarity model based on the distance between the rainfall and runoff was built to compute the minimum value $\sigma$ of the objective function (defined as $\Phi$ ).

The objective function is

$$
\Phi=\sum_{i=1}^{n}\left|X_{i}-Y_{i}\right|
$$

The similarity function is

$$
\sigma=\min \Phi
$$

$X_{i}$ represented the annual runoff values, and $Y_{i}$ was the annual rainfall values. In this paper, the " $n$ " refers to 10 years from 2001 to 2010. One has

$$
\begin{aligned}
\Phi= & \sqrt{(2001-2001)^{2}+(a-b)^{2}}+\cdots \\
& +\sqrt{(2010-2010)^{2}+\left(a-b+c_{9}\right)}
\end{aligned}
$$

Let $a-b=Q$, then the objective function could be simplified as

$$
\Phi=|Q|+\left|Q+c_{1}\right|+\cdots+\left|Q+c_{9}\right| .
$$

\section{Results and Discussions}

A simple similarity model was established to calculate the minimum value of Euclidean distance between rainfall and runoff. The solution results showed that the corresponding constraint or range also presented an interesting and stable trend as shown in Table 1. For the even-numbered years, the corresponding constraint condition was a range or interval, and for the odd-numbered years, the corresponding constraint condition was just the boundary value of range.

The minimum values of similarity between rainfall and runoff by calculating the objective function were shown in Figure 5. It was noticed that the evolution of the minimum value of similarity versus the time approximately followed the linear distribution. The least-squares method was used to fit the initial and denoised time series. A model of rainfall and runoff similarity relation in the upstream Red River Basin was determined. The formula was as follows:

$$
\delta=m \times t-c .
$$

Then we take parameters' sensitivities on the results into consideration. In case of long data ( 9 years) with noise, $m_{1}=1350.7$, and $c_{1}=2703600$, and in denoised case, $m_{1}=1339.2$, and $c_{1}=2680500$, while, in case of short data ( 8 years) with noise, $m_{1}=1276.6$, and $c_{1}=2555200$, and in denoised case, $m_{1}=1265.8$, and $c_{1}=2533500$. Clearly, the key parameters of this model showed some fluctuations. However, this method of modeling could be applied in other regions.

In different regions, the rainfall-runoff similarity still existed $[6,7]$. Although this paper investigated the upstream Red River Basin, other sets of values in other regions also could be calculated by using this model, but the parameters of model would not be the same.

The following figures showed the fitting curves and correlation coefficients.

In order to verify the accuracy of the model, we calculated the relative error using the data of 2010. The predicting value of similarity was 11307, and the observed value was 12172 . In fact an accumulated error from 2001 to 2010 was obtained with the annual error at 86.5. We acquired the relative error 0.0071 , by the ratio between the annual error and observed value.

Figure 7 clearly showed that the annual mean similarity took a gradually rising trend. Even if it was difficult to separate which part of this annual mean similarity increase was due to climate changes alone or to human impact on ecological environment. According to the historical data records, in 2005, it was often the wettest in the summer. However, Yunnan Province in China suffered the most serious early summer drought in the past 50 years. Figure 6 showed clearly the rainfall was increasing, and the runoff 


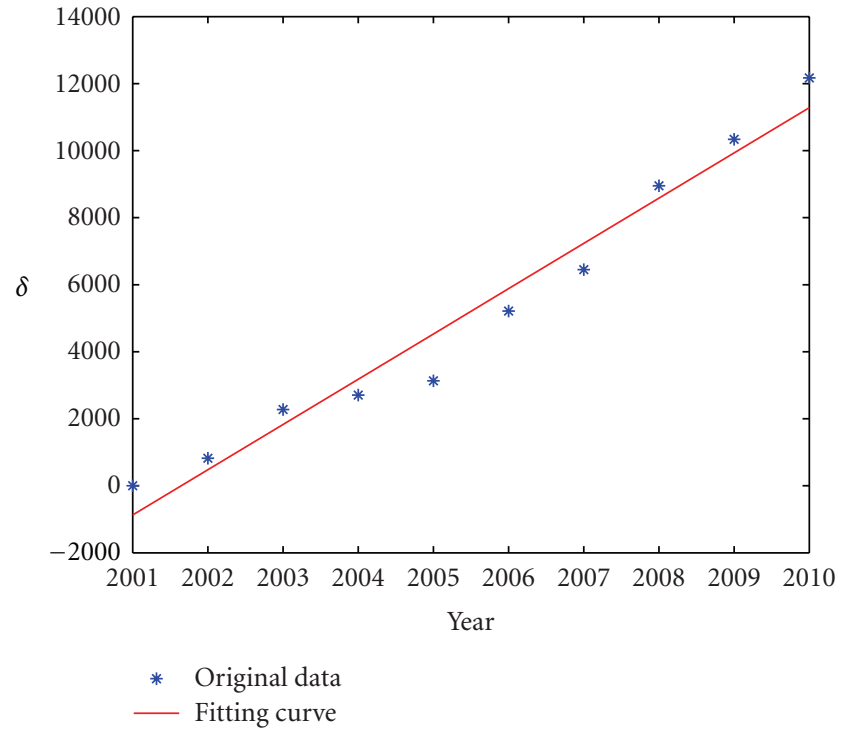

(a)

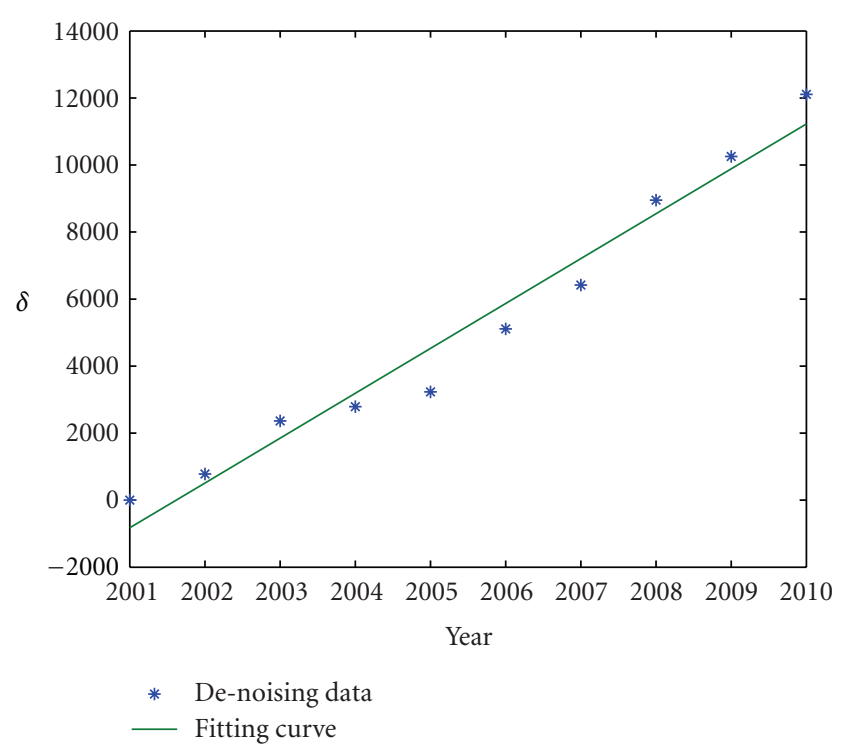

(b)

FIGURE 5: Fitting of initial (a) and de-noising (b) data with the correlation coefficient 0.982 and 0.983.
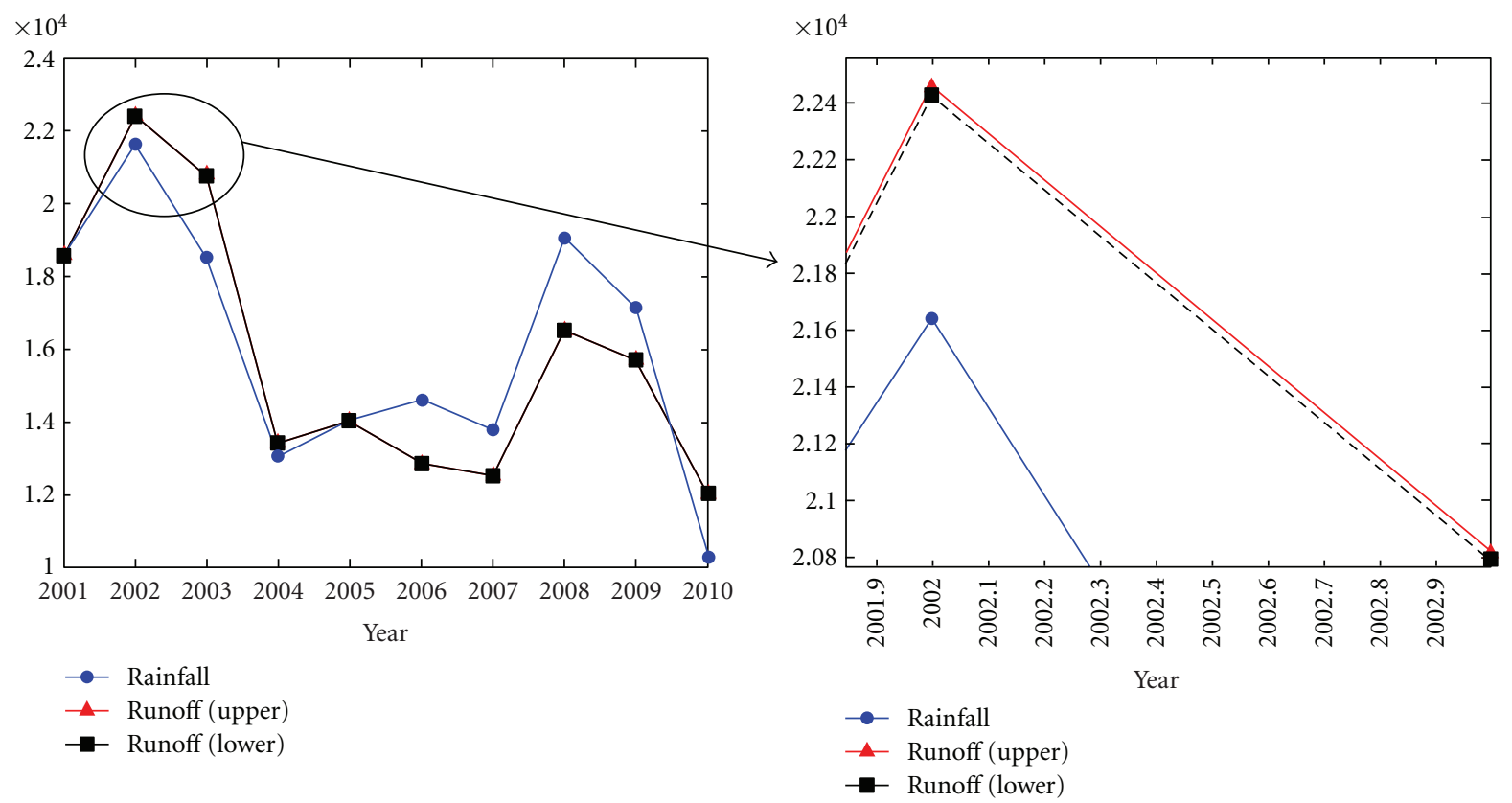

FIgURE 6: The similar patterns of rainfall and runoff at the minimum distance from 2001 to 2010.

was decreasing. At the same time, this index of annual mean similarity presented a fluctuation from 2005.

In addition, according to water resources bulletin of Yunnan Province from 2002 to 2004, the years 2002 and 2004 belonged to years of average river water level. But the year of 2003 was relatively dry, which suffered the most serious drought in the last five years. Clearly in Table 1, the particular sets from 2002 to 2004 showed some fluctuations. While in 2003, the constraint condition of similarity model arrived the maximum point. Figure 7 further showed the fluctuation of the annual mean similarity in 2003. It was very interesting to study the changes of our ecological environment by comparison of similarity between rainfall and runoff.

\section{Summary}

In this paper, we studied the rainfall-runoff similar patterns in the upstream Red River Basin. The normalized rainfallrunoff values were obtained by a simple linear transformation. A model of rainfall-runoff similarity was built to determine the minimum of the Euclidean distance between rainfall and runoff. Both original and denoised time series 


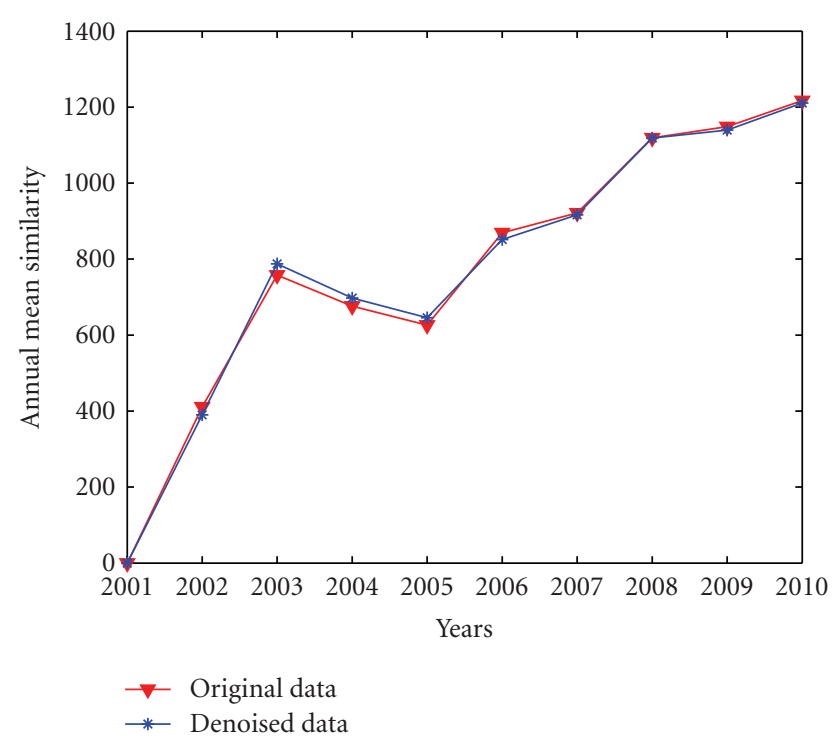

FIGURE 7: Plots of annual mean similarity versus years.

by thresholding the wavelet coefficients were applied to verify this model. The results indicated that the rainfallrunoff similarity was of a good time-correlated characteristic with a high correlation coefficient. When the minimum value of similarity model was obtained, the corresponding constraint or range also presented an interesting and stable trend. The annual mean similarity showed a gradually rising trend; in other words, the minimum distance between rainfall and runoff patterns in the upstream Red River Basin was increasing. All these changes were caused by the comprehensive influences of climate change and human activities on rainfall-runoff similarity.

Studying the similar relations of rainfall and runoff was of great significance. According to our research results, the constraint or range for meeting the minimum distance of rainfall-runoff similarity was getting smaller and smaller. However, the objective function value of similarity of rainfall and runoff always followed a linear distribution, and the next annual similar relationship of rainfall and runoff could be predicted. In particular, the trend of annual mean similarity reflected the impact of external environment changes on hydrology and water resources system.

\section{List of Symbols}

$X: \quad$ Input signal

$X D$ : Denoised time series

SNR: Signal-to-noise ratio

a: Annual rainfall in 2001

$X_{i}$ : The annual runoff values

$n: \quad$ Years from 2001 to 2010

$c_{i}$ : The constant

$\sigma:$ The minimum value of objective function

$\Phi: \quad$ Objective function

$Y: \quad$ Normalized data $b$ : Annual runoff in 2001

$Y_{i}$ : The annual rainfall values

Q: The difference of $a$ and $b$.

\section{Acknowledgments}

This research is supported by the National Natural Science Foundation of China (Grant no. 51174105). The authors also deeply appreciate the helpful review comments and suggestions by anonymous reviewers.

\section{References}

[1] D. M. He, S. H. Wu, and H. Peng, "A study of ecosystem changes in Longitudinal Range-Gorge Region and transboundary eco-security in southwest China," Advances in Earth Science, vol. 20, no. 3, pp. 338-344, 2005.

[2] W. A. Welderufael, P. A. L. Le Roux, and M. Hensley, "Quantifying rainfall-runoff relationships on the Dera Calcic Fluvic Regosol ecotope in Ethiopia," Agricultural Water Management, vol. 95, no. 11, pp. 1223-1232, 2008.

[3] O. Kisi, J. Shiri, and M. Tombul, "Modeling rainfall-runoff process using soft computing techniques," Computers \& Geosciences, vol. 51, pp. 108-117, 2013.

[4] D. Labat, R. Ababou, and A. Mangin, "Rainfall-runoff relations for karstic springs-part I: convolution and spectral analyses," Journal of Hydrology, vol. 238, no. 3-4, pp. 123-148, 2000.

[5] M. P. Rajurkar, U. C. Kothyari, and U. C. Chaube, "Modeling of the daily rainfall-runoff relationship with artificial neural network," Journal of Hydrology, vol. 285, no. 1-4, pp. 96-113, 2004.

[6] W. Sven Lavado Casimiro, J. Ronchail, D. Labat, J. C. Espinoza, and J. L. Guyot, "Basin-scale analysis of rainfall and runoff in Peru (1969-2004): Pacific, Titicaca and Amazonas drainages," Hydrological Sciences Journal, vol. 57, no. 4, pp. 625-642, 2012.

[7] J. C. Zhang, J. Jiang, D. P. Liu, and L. Donald DeAngelis, "Vegetation coverage influence on rainfall-runoff relation based on wavelet analysis," Journal of American Science, vol. 5, no. 2, pp. 97-104, 2009.

[8] T. Partal and M. Küçük, "Long-term trend analysis using discrete wavelet components of annual precipitations measurements in Marmara region (Turkey)," Physics and Chemistry of the Earth, vol. 31, no. 18, pp. 1189-1200, 2006.

[9] J. Wang and J. Meng, "Research on runoff variations based on wavelet analysis and wavelet neural network model: a case study of the Heihe River drainage basin (1944-2005)," Journal of Geographical Sciences, vol. 17, no. 3, pp. 327-338, 2007.

[10] W. C. Boughton, "Effect of data length on rainfall-runoff modeling," Environmental Modelling \& Software, vol. 22, no. 3, pp. 406-413, 2007.

[11] L. H. C. Chua and T. S. W. Wong, "Improving event-based rainfall-runoff modeling using a combined artificial neural network-kinematic wave approach," Journal of Hydrology, vol. 390, no. 1-2, pp. 92-107, 2010.

[12] G. Alaerts, J. van Erps, S. Pieters et al., "Similarity analyses of chromatographic fingerprints as tools for identification and quality control of green tea," Chemometrics in Chromatograph, vol. 910, pp. 61-67, 2012.

[13] G. F. Lin and C. M. Wang, "A nonlinear rainfall-runoff model embedded with an automated calibration method-part 1: the model," Journal of Hydrology, vol. 341, no. 3-4, pp. 186-195, 2007. 
[14] J. Yu, C. Yang, C. Liu et al., "Slope runoff study in situ using rainfall simulator in mountainous area of North China," Journal of Geographical Sciences, vol. 19, no. 4, pp. 461-470, 2009.

[15] G. Cao, J. Wang, L. Wang, and Y. Li, "Characteristics and runoff volume of the Yangtze River paleo-valley at Nanjing reach in the Last Glacial Maximum," Journal of Geographical Sciences, vol. 20, no. 3, pp. 431-440, 2010.

[16] X. Lin, Y. Zhang, Z. Yao et al., "The trend on runoff variations in the Lhasa River Basin," Journal of Geographical Sciences, vol. 18, no. 1, pp. 95-106, 2008.

[17] J. Li and P. Feng, "Runoff variations in the Luanhe River Basin during 1956-2002," Journal of Geographical Sciences, vol. 17, no. 3, pp. 339-350, 2007.

[18] Y. Jiang, C. Zhou, and W. Cheng, "Streamflow trends and hydrological response to climatic change in Tarim headwater basin," Journal of Geographical Sciences, vol. 17, no. 1, pp. 5161, 2007.

[19] G. Mahé and J. E. Paturel, “1896-2006 Sahelian annual rainfall variability and runoff increase of Sahelian Rivers," Comptes Rendus Geoscience, vol. 341, no. 7, pp. 538-546, 2009. 

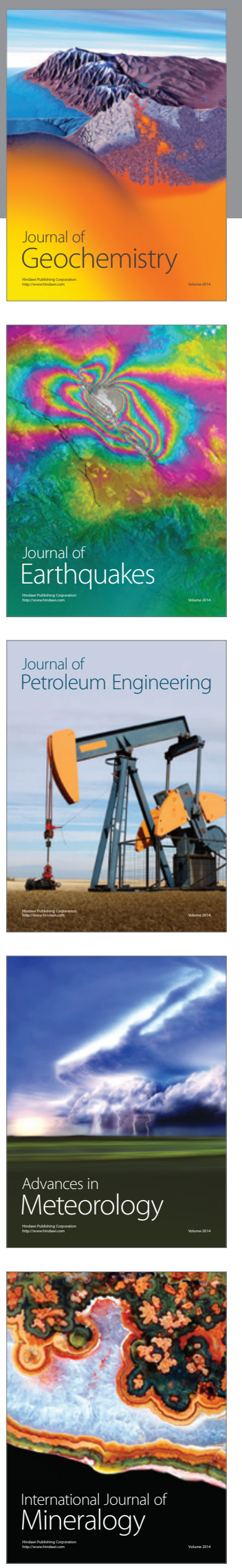
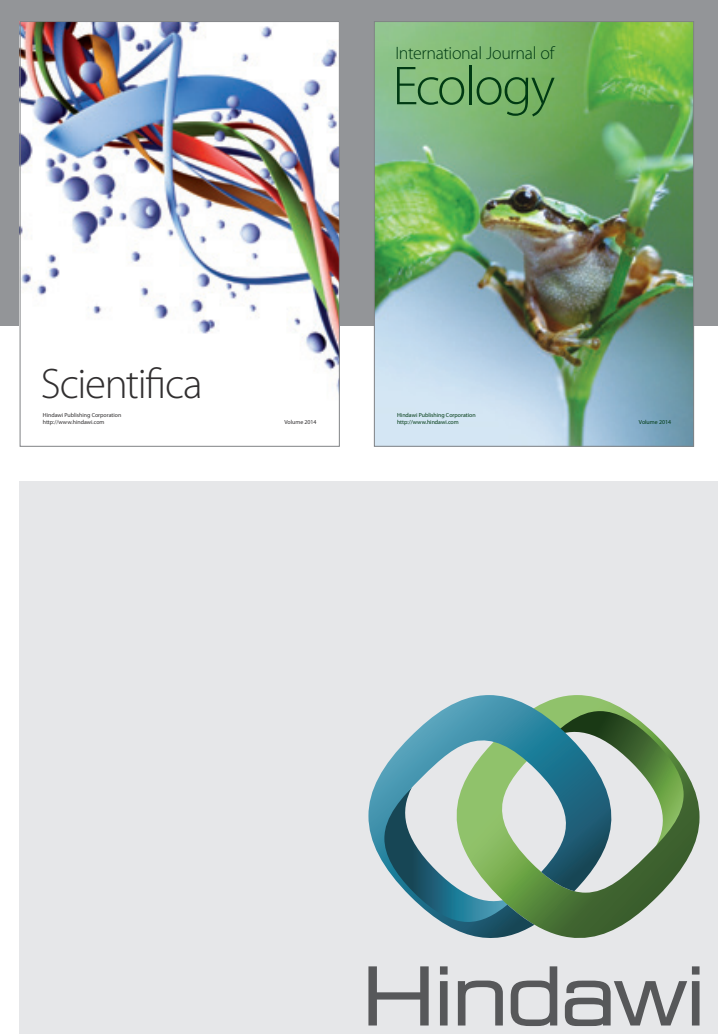

Submit your manuscripts at http://www.hindawi.com
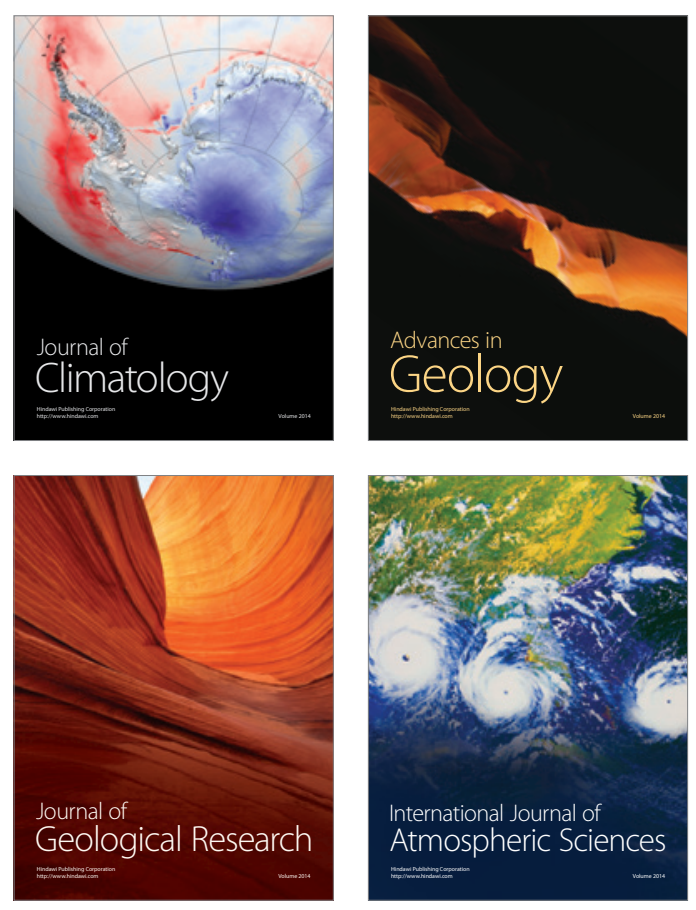
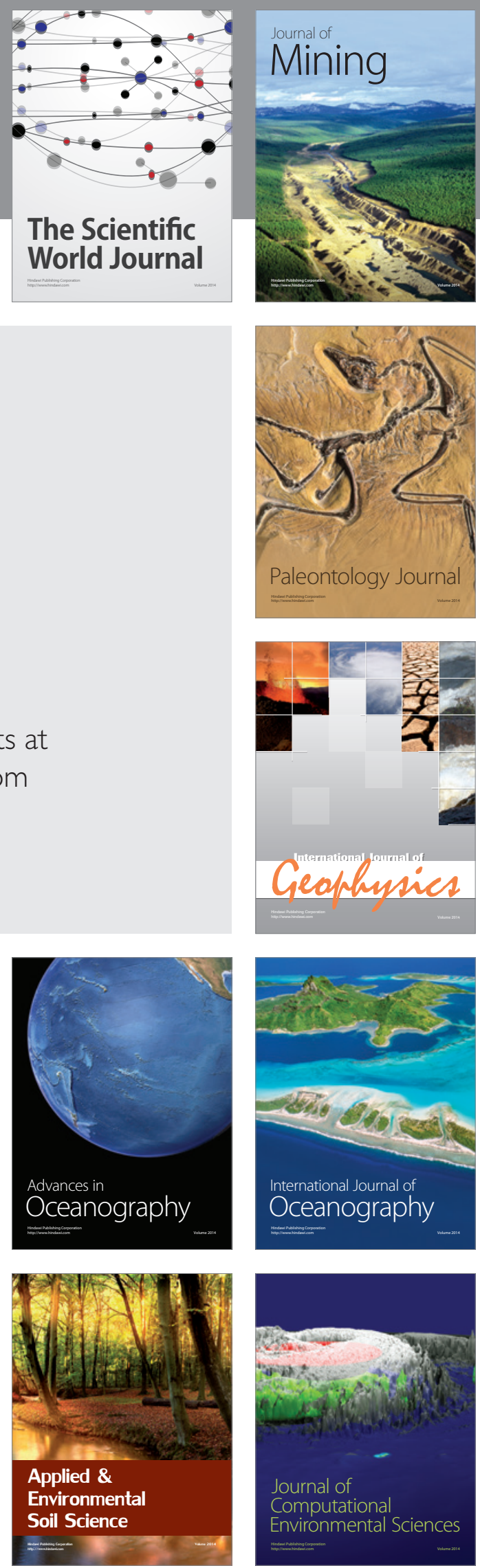